\title{
El anuncio de Ortega y Gasset del progreso regresivo hacia el individualismo en red*
}

\author{
Luis Núñez Ladevéze \\ Universidad CEU San Pablo \\ ladeveze@telefonica.net \\ Margarita Núñez Canal
}

ESIC Business \& Marketing School

margaritanunez@esic.edu

Ignacio Álvarez de Mon

IE Instituto de Empresa

ignacio.alvarezdmon@ie.edu

Fecha de presentación: julio de 2020

Fecha de aceptación: abril de 2021

Fecha de publicación: diciembre de 2021

Cita recomendada: NúŇEz Ladevéze, L.; NúŇEZ Canal, M. y Álvarez de Mon, I. (2021). «El anuncio de Ortega y Gasset del progreso regresivo hacia el individualismo en red». Anàlisi: Quaderns de Comunicació i Cultura, 65, 87-101. DOI: <https://doi.org/10.5565/rev/ analisi.3343>

\section{Resumen}

En la Meditación de la técnica y La rebelión de las masas, Ortega y Gasset anticipó que los medios de comunicación producían una interdependencia mundial que actualmente denominamos "globalización». Siguiendo la crítica orteguiana al idealismo, el texto concibe el medio de comunicación como una prótesis añadida al sensorio humano que amplía ilimitadamente el campo de observación ceñido a los sentidos. El acceso generalizado de otras culturas al conocimiento científico europeo y la propagación de las prótesis técnicas en la interacción de la red —un ámbito global de relaciones cara a cara sin distanciagenera una alteración en la supremacía cultural que se desplaza de Occidente a Oriente, lo

* Este artículo responde al marco teórico y a la revisión de textos del proyecto coordinado CONVERED De las audiencias televisivas a las redes sociales: Convergencia de medios en la sociedad digital. (CSO2016-74980-C2-1-R), financiado por el programa de I+D del MINECO con cargo a fondos europeos FEDER. Está integrado en el plan de actividades PROVULDIG 2 Nuevos escenarios de vulnerabilidad digital: alfabetización mediática para una sociedad inclusiva (H2019/HUM5775), financiado con cargo a fondos europeos por la CAM. 
cual fue anunciado hace un siglo por el filósofo español al presagiar que Europa no mandaría en el mundo.

Palabras clave: globalización; rebelión de las masas; aldea global; eurocentrismo; autonomía científica

Resum. L'anunci de José Ortega y Gasset del progrés regressiu cap a l'individualisme en xarxa

En la Meditación de la técnica i La rebelión de las masas, Ortega y Gasset anticipà que els mitjans de comunicació produïen una interdependència mundial que actualment anomenem «globalització». Seguint la crítica orteguiana a l'idealisme, el text concep el mitjà de comunicació com una pròtesi afegida al sensori humà que amplia il.limitadament el camp d'observació cenyit als sentits. L'accés generalitzat d'altres cultures al coneixement científic europeu i la propagació de les pròtesis tècniques en la interacció de la xarxa —un àmbit global de relacions cara a cara sense distància- generen una alteració en la supremacia cultural que es desplaça de l'Occident a l'Orient, la qual cosa va ser anunciada fa un segle pel filòsof espanyol en presagiar que Europa no manaria al món.

Paraules clau: globalització; rebel-lió de les masses; veïnatge universal; eurocentrisme; autonomia científica

Abstract. Ortega y Gasset's message of regressive progress toward internet-based individualism

In his works Meditación de la técnica (Meditations on Technique) and La Rebelión de las masas (Revolt of the Masses), Ortega y Gasset predicted that the communication media would produce global interdependence, nowadays referred to as "globalisation". Following the Orteguian criticism of idealism, the text sees the media as a prosthesis added to the human sensorium which endlessly broadens the field of observation limited to the senses. Widespread access to European scientific knowledge by other cultures, as well as the propagation of technical aids resulting from interaction with the internet - a global sphere of face-to-face relationships regardless of distance - is displacing the cultural supremacy of the West, as the Eastern world appropriates scientific and technical knowledge, a situation predicted a century ago by Ortega y Gasset when he warned that Europe would no longer rule the world.

Keywords: globalisation; revolt of the masses; global village; eurocentrism; scientific autonomy

\section{Lenguaje, medios y prótesis}

Situados en la distancia del cara a cara, los sentidos suelen estar más abiertos a recibir que dispuestos a filtrar. Si nos encontramos en un cine, nos aislamos para centrarnos en la pantalla. La apertura y el aislamiento orgánicos son relativos, requieren una disposición según el entorno en que nos hallemos. La disposición no es decisión, modula la atención que se adopta en una situación sobre la que también se ha optado. Las disposiciones que procuramos no están determinadas necesariamente por las situaciones, que suelen ser variables y combinarse con diferentes actitudes. La situación puede cambiar fácilmente. Paseamos, miramos un escaparate, hablamos con un amigo, leemos un cartel, saludamos a un transeúnte. Las actitudes pueden mudar en una 
misma situación. Podemos reflexionar, leer, ensimismarnos ante un monumento en la calle, mirar distraídos un anuncio o saludar inadvertidamente al conocido con quien nos cruzamos. El entorno tiene reglas de funcionamiento, pero no gobierna nuestra actitud ni la disposición, aunque habitualmente tratamos de amoldar nuestra presencia a pautas que pueden ser o no institucionales. Eso nos socializa. En una sala de cine o durante una conferencia sería inoportuno dejar que sonara nuestro móvil. En un autobús sería molesto para otros, pero no contravendría una regla no escrita. Ser social siempre incluye el cumplimiento de reglas, hábitos, formalidades corteses, principios de urbanidad, aunque no siempre lo hagamos o porque procuramos que cambien si cambian las circunstancias o si las consideramos inapropiadas. Estos son los «usos» inconscientemente o conscientemente admitidos. La sociedad nos habitúa a seguir una conducta impuesta, impersonal en cualquier circunstancia, y eso es lo que para Ortega y Gasset constituye «el hecho social [...] todo lo social es una máquina que mecánicamente conserva y fosiliza la vida humana personal» (Ortega, 2010: X, 140 y 282). De aquí que el lenguaje mismo, aunque nos da la impresión de que nace de nuestro mundo interior y que expresa el pensamiento propio, no el ajeno, tenga ese componente mecanicista, sea un «lazo social que constituye la lengua $[. .$.$] no es$ libre, es impuesto [...] basta con decir que es un producto de fuerzas sociales para que se vea claramente que no es libre» (Saussure, 1971: 57, 135 y 139). La noción que Ortega suministra sobre el hecho social es tan próxima a Saussure que el filósofo la aplica al estudio del «saludo de cortesía» (Ortega, 2010: X, 269 y s.) y Saussure (1971: 131) asegura que «los signos de cortesía [...] no están menos fijados por una regla» de lo que lo está el lenguaje.

Estas líneas pretenden situar un ámbito a la efectividad del comentario y la crítica social mostrando que la utilidad que presta un medio, ya sea un miembro del cuerpo, la asignación de un significado a un significante, una regla institucional de cortesía o un artilugio como el móvil, da lugar a tendencias socialmente conflictivas. Como punto de partida nos servimos del concepto de "uso", propuesto por Ortega y Gasset, por ser congruente con la concepción saussureana de la lengua como imposición de la colectividad. Esta perspectiva permite vincular los distintos sistemas de reglas sociales como especies fragmentarias en la diversidad social de usos colectivos. Unifica, por tanto, la dimensión macrosociológica con la microsociología de los estudios sobre formación del self en Mead (1991) y de Goffman (1981). Unifica el análisis de larga distancia propio de la lingüística y de la sociología teóricas con el estudio a corta distancia que, a partir de la noción de grupos primarios, se aplica al análisis de los usos lingüísticos y de los rituales sociales en el estudio de la comunicación cara a cara (Cooley, 1906; Núñez Ladevéze y Vázquez Barrio, 2020), entendidas «como la influencia recíproca de un individuo sobre las acciones del otro cuando se encuentran ambos en presencia física inmediata» (Mead, 1991: 27).

Planteamos, no obstante, una particularidad presupuesta por los pragmatistas y presente en la reflexión orteguiana de la técnica y de McLuhan sobre 
los medios como prolongación de los sentidos. Basta leer Ideas y creencias o En torno a Galileo para entender el self como un instrumento de mediación del organismo consigo mismo, por lo que si las relaciones del self consigo mismo son mediadoras, han de serlo a fortiori las relaciones cara a cara. La diferencia estriba en que el organismo, entendido como sistema de mediación con uno mismo y con los demás, es constante, aunque no lo sean sus productos mediadores, ideas y acciones, emanaciones variables y transitorias, donde el self se desenvuelve acoplándose a medios no orgánicos. En tanto uso social, una idea, una palabra, el alcance de una relación cara a cara, fruto de una mediación mudable, no puede predeterminarse. Pero si, como entiende Goffman (1981), esta mediación está vinculada directamente a la efectividad del organismo, su forma de mediación es constante. De aquí que las relaciones cara a cara en presencia física siempre se han tenido en cuenta como constantes. Para centrar este planteamiento pragmático en Ortega nos valemos del análisis que ofrece de la corporalidad en Husserl en el capítulo cuarto de $E l$ hombre y la gente, donde propone el concepto no tematizado hasta ahora de "campo pragmático». Allí escribe que el cuerpo «es mío porque me es el instrumento inmediato de que me sirvo para habérmelas con las demás cosas». El campo pragmático es el entorno de interacción que se abre a cada organismo, y, a la vez, a través de la integración de los organismos en una red global de comunicación de relaciones cara a cara, el campo pragmático pasa a ser un campo de interacción global.

En esta presentación orteguiana de la "corporalidad», que permite distinguir entre el cuerpo y los medios que usa, emplazamos el tema de las prótesis sirviéndonos de la Meditación de la técnica orteguiana. Las prótesis se adhieren al organismo, pero no son orgánicas. Entendemos, en consecuencia, la red digital como un procedimiento de mantener relaciones cara a cara a través de una prótesis artificial ańadida a la actividad del organismo corporal. Entonces, la interacción cara a cara en presencia física y las relaciones interactivas e interpersonales en la red se hacen más similares e indiscernibles de las relaciones entre grupos primarios. Como se ha dicho, la red actúa como un vecindario de proximidad a distancia (Núñez Ladevéze, Vázquez y Núñez, 2019).

Todo medio no orgánico prolonga la actividad orgánica artificialmente, por lo que podría articularse a otro artefacto mediador (McLuhan, 1996). En tanto producto de un organismo, una idea es un medio, algo que no estaba ahí de antemano, que no pertenece al mundo cuyo entorno nos abarca. Esta singularidad de la idea como producto adoptada de la distinción orteguiana entre "idea" $y$ "creencia» es relevante: "todas las palabras y giros fueron inicialmente inventos individuales que luego se degradaron en usos mecanizados» (Ortega, 2010: X, 310). El lenguaje, como medio que expresa ideas, tiene una composición peculiar, nace de la «invención» personal y se nutre de la «coacción social»: «la lengua, el habla, es lo que la gente dice, es el ingente sistema de usos sociales establecido por una colectividad. El individuo, la persona, desde que nace está sometido a la coacción lingüística» (Ortega, 2010: $\mathrm{X}, 309)$, pero no solo a ella, sino también a la coacción del conjunto de reglas 
sociales que forman los usos establecidos: «todos nuestros gestos provienen de nuestra sociedad, son movimientos que hacemos porque la gente los hace» (Ortega, 2010: X, 313).

Conviene, por tanto, tomar cautelas respecto del lenguaje como expresión de ideas. Por muy relevante que sea, no es un caso excepcional de objetivación social de intenciones subjetivas. La mediación no se da solo en el lenguaje, sino también en el uso de los órganos corporales, que, al realizar una tarea, expresan una intención generada por una idea. De aquí que, para Ortega - como para los gramáticos que han estudiado indistintamente la significación-, la entonación, la gesticulación y las pausas son inherentes al lenguaje (Ortega, 2010: X, caps. VII y X). Aunque los tonos de la voz no pertenecen a la arbitrariedad significativa, añaden un significado arbitrariamente simbolizado a la actividad fónica, a los que los gramáticos dan carta de naturaleza para separar palabras o clasificar oraciones. Estos significados pueden ser diversamente entendidos según los contextos como tipos de acciones humanas distintas de su literalidad. «A todas las palabras les acontece algo parecido, su significación auténtica es algo ocasional» (Ortega, 2010: X, 302). Esta diferencia entre significado literal y significado contextual concreto la distribuyó Austin (1971) entre acto locutivo y acto inlocutivo. Permite reforzar más la relación entre Ortega y el pragmatismo ya advertida y discutida por Armenteros (2004) y Gutiérrez Simón (2020). La idea, el concepto, el símbolo, la expresión, el gesto y el ademán son medios, pero no solo de comunicación con los demás, sino que, de resultas de una actividad corporal que realizan los miembros cuando llevan a cabo actividades intencionales como pescar, jugar o cocinar, son —esta es otra aportación de la Meditación de la técnica - también medios de participación en la naturaleza. Medios para rectificar, modular o adaptar el entorno a las mutables exigencias humanas.

Un símbolo es un medio ideado por la actividad humana para atribuir una función de uso a un significante. Un micrófono también es un medio, un producto de la actividad humana que atribuye una función de uso a un objeto. Desde la perspectiva de la Meditación de la técnica, estos dos tipos de mediación pueden acoplarse y, de hecho, se acoplan, aunque no lo hagan recíprocamente. Por eso hay que distinguir entre medios naturalmente corporales y prótesis. El micrófono es una prótesis, un medio para ampliar la difusión de la voz, pero la voz no es una prótesis, no es un medio para el micrófono. La actividad humana es mediadora, pero se puede distinguir la realizada directamente con lo allende al organismo como mediación orgánica y las prótesis que se superponen artificialmente unas a otras para acoplarse a esta actividad. Lo relevante ahora es que toda actividad específicamente humana es mediada, consiste en la mediación entre «ideas» (ocurrencias) y objetos que la intencionalidad ańade como prótesis para ampliar la eficacia extrahumana de la corporalidad.

Centramos este análisis de las relaciones cara a cara virtuales considerando la red como una prótesis global a partir de las posibilidades que ofrece la filosofía orteguiana de la técnica para el estudio de esta nueva situación comuni- 
cativa, en que las relaciones microsociales entre vecinos se confunden en la red con la perspectiva macrosociológica como relaciones de interdependencia colectiva en un campo pragmático globalmente unificado. Ortega adelantó, en La rebelión de las masas, la imagen de la aldea global y previó la globalización como una relación de ubicuidad entre individuos a distancia: «reconocemos hoy en cualquier punto del globo la más efectiva ubicuidad. Esta proximidad de lo lejano, esta presencia de lo ausente, ha aumentado en proporción fabulosa el horizonte de cada vida» (Ortega, 2005: IV, 394).

\section{El nuevo entorno de los medios para la crítica social}

Toda actividad propiamente humana es mediadora de la interacción entre el hombre y su entorno. La mano es el medio de realizar ideas conforme a la regla procurada por la intención que la dirige. Si todo signo es signo de algo, y ese algo está fuera del acto significativo, el «de» de esa relación señala el producto de una actividad que no contiene lo producido, sino que queda fuera de ella. Ese fuera de es un fuera del hombre, es decir, reside en lo que solemos llamar "naturaleza», en la que el hombre se integra. Al hablar de «actividad» aludimos a la espontaneidad del hombre que actúa. No se trata de una actividad peculiar, pues todos los organismos son manifestaciones de la actividad que los unifica y los diferencia de los demás, pero al hablar de significación y de intencionalidad nos referimos a una actividad que no solo emana, sino que también produce su emanación como algo diferenciable de sí mismo y de la actividad que realiza. Al igual que simbolizar, idear funciones distingue al organismo que piensa. La conciencia intencional sabe lo que hace, lo comprende y, porque lo comprende y lo sabe, lo hace. El Homo utilis no difiere del Homo faber ni del Homo loquens. Como el hacer, también el hablar es una forma de religarse entre los hombres y de desligarlos de la naturaleza de que forman parte.

$\mathrm{Al}$ pretender entender la razón como una facultad desencarnada, desgajada de la unidad que siente y piensa, el racionalismo no pudo explicar la mediación humana. La intencionalidad es una actividad orgánica. Cuando se ejecuta la intención, lo pensado queda expuesto fuera del sujeto pensante, pero forma parte del sujeto que piensa en tanto objeto pensado. Lo pensado es un medio intencional de la finalidad que el miembro ejecuta. Lo que está fuera de la actividad realizada encuentra su exteriorización en un mundo ajeno a esa actividad, pero sobre el que la acción que lo ejecuta recae para modificarlo. La persona que piensa utiliza sus miembros como medios de hacer, y ese "hacer» es un hacer, un llevar a la práctica la idea que se tiene de lo que se quiere hacer. Toda ideación es un medio de otra cosa que queda fuera de ella misma, de manera que los propios órganos sensoriales son medios con relación a la actividad que emprenden. De aquí que Ortega asegure que el hombre no es una inteligencia racional, sino un ser vital que hace cosas razonando (Ortega, 2006: V, 573).

A las prótesis les es aplicable entonces el supuesto de que su función consiste en satisfacer un propósito y de que su uso está principalmente condicio- 
nado por la función intencional ideada por alguien. Pero, aunque la tarea de un medio sea asignada por o para un uso, el uso no deja de ser transitorio, por lo que también lo son el medio o prótesis y la función que realice. Por tanto, la tendencia a predeterminar los efectos derivados del uso del medio de comunicación suele ser un ejercicio inútil. Sin embargo, ha sido frecuente interpretar que la utilidad que un medio de comunicación brinda haya de vincularse a un uso imperativo (Becker, 1981). La idea de que, a partir de la reflexión sobre el medio, se pueda invocar una norma imperativa para que pueda aprovecharse su posible potencial en una dirección prevista de antemano como interés general de la colectividad, ha sido muy frecuente y lo sigue siendo, como han mostrado los estudiosos que han clasificado modelos de democracia a partir de la explotación del potencial de los medios (Van Dijk, 2000; Zaremberg y Welp, 2020).

Vana pretensión, no solo porque el medio, llamado a renovarse, sea transitorio, sino también porque esa renovación, que emerge de la inventiva, es imprevisible. Como instrumento realiza funciones mudables, adaptables a distintas situaciones compatibles con las actitudes del usuario (Núñez Ladevéze, Vázquez y Núnez Canal, 2019). No hay un modo fijo de afrontar la transitoriedad, ni son fijos los cauces que puedan preverse para realizarla. La indeterminación procede de que nada asegura una finalidad estable. Su función puede caducar, porque puede caer en desuso o porque puede ser reemplazada. De aquí que las prótesis sean inventadas para resolver inconvenientes en situaciones mudables, que lo mismo pueden simplificarse que complicarse. Siempre cabe abordar nuevas tareas o satisfacer inquietudes imprevistas a través de la renovación, como también pueden darse retrocesos cuando lo que parecía imprescindible se convierte en inconveniente. Lo que está ocurriendo con los programas de defensa ecológica son ejemplos patentes de una preocupación regresiva sobre el valor de utilidad de medios que antaño parecieron imprescindibles para el mantenimiento de un sistema de vida (Núñez Ladevéze, Vázquez y Núñez Canal, 2019).

Si la mediación es una actividad del organismo humano ligada al uso de medios, las prótesis son entonces una especie del género "medios», cuya vigencia no puede predeterminarse. Como no hay acción que no dependa de o no se realice sin mediación, cualquier trabajo sobre medios ha de basarse en alguna clasificación que incluya a los órganos como instrumentos corporales permanentes y a las prótesis como prolongaciones variables de los miembros. Aunque nos limitemos a las prótesis como medios artificiales, artefactos que expanden la habilidad del Homo habilis, la mediación no deja de coincidir en ser una actividad mediadora desnaturalizante, que desliga al hombre de su entorno. La tarea de mediar consiste en introducir nuevos medios para desnaturalizar.

\section{La enajenación de las masas}

Buena parte de la crítica cultural del siglo XX se centró en los medios de comunicación masivos para cebarse en la cultura de masas. Enjuició la fun- 
ción del medio como si debiera responder a algún imperativo prefijado. Los críticos se enfrentaron a un aspecto del progreso tecnológico que vinculaba la imagen y el espectáculo a la pasividad de la audiencia ante las pantallas. La masa era un destinatario pasivo, adocenado, incapaz de evitar su dependencia. Muchos críticos de los efectos sociales de este proceso de interacción interpretaron que el medio comunicativo actuaba como un instrumento de enajenación colectiva por estar en manos de los propietarios del capital (Núñez Ladevéze, Vázquez y Álvarez de Mon, 2019).

Asociaron las audiencias de los productos elaborados en serie por la industria cultural a la relación de dependencia pasiva del oligopolio de las empresas emisoras. Solía decirse que el bajo nivel cultural de las audiencias estaba determinado por los intereses del oligopolio en mantener la reducción de la oferta para impedir la libre elección y la capacidad de respuesta del oyente de radio o del espectador de los emergentes medios audiovisuales. Se facilitaba la sumisión al sistema capitalista de producción excitando las emociones, sirviendo a sentimientos en lugar de transmitir conocimientos, manteniendo la atención sin suscitar la reflexión ni la capacidad crítica. Se aducía que el medio era un instrumento que facilitaba el entumecimiento colectivo por ser producido por una industria que aseguraba una relación receptiva promotora de la masificación del gusto popular. Los capitalistas emisores «crean modelos para la actuación y la ilusión de que algo se dice en medio de la mudez [...] Las máquinas de opinión masiva, los periódicos, la radio, el cinematógrafo, la televisión, tienen la misión de dirigir a los atrapados y de relevarlos de toda decisión que no forma parte de su trabajo» (Horkheimer, 1970: 29-30).

La asociación entre masa, espectáculo, imagen auditiva y visual, emocionalidad y pasividad se acentúa con la televisión. Tanto la Escuela de Fráncfort como el funcionalismo estructural se centraron en que el destinatario no interactuaba con el emisor. Se limitaba a consumir pasivamente lo que se le ofrecía. Diferenciaban la masa de oyentes y espectadores de la cultura alfabetizada, libresca, concentrada y reflexiva. El libro era el medio cultural representativo de «la cultura de los estratos superiores, cuya base era la desigualdad», ahora «forzada a adaptarse a las exigencias de la nueva sociedad de masas» (Horkheimer, 1970: 31). Spengler escribía en La decadencia de Occidente:

[...] la democracia ha sustituido totalmente, en la vida espiritual de las masas populares, el libro por el periódico. El mundo de los libros, con su riqueza de puntos de vista —riqueza que obligaba al pensamiento a elegir y a criticar-, no es ya propiedad real más que de reducidos círculos. El pueblo lee un periódico, su periódico, que penetra diariamente en millones de ejemplares en todas las casas, ata de buena mañana todos los espíritus a su poder, hace olvidar los libros que aún aparecen en el horizonte del individuo. (Spengler, 1923: 4. ${ }^{\mathrm{a}}$ parte)

Debord (1995) contrapuso la sociedad del espectáculo a la del conocimiento. Como evidentemente leer no es una actividad transitiva, hubo que 
encontrar la raíz de la diferencia entre hablar y leer. No podía ser la reciprocidad, porque, para hablar, normalmente, hay que escuchar. El hablar es dialógico, pero la lectura requiere habitualmente una atención individualizada que prescinde del intercambio discursivo. Se encontró la diferencia en la reflexión. Todavía a finales de siglo aplicaba Sartori, en Homo videns (1998), esta contraposición entre mirar y leer. El lector es introspectivamente reflexivo, pero mirar es pasivo.

Si la capacidad de ensimismarse es una cualidad humana (Ortega, 2010: $\mathrm{X}, 139$ y s.), el ánimo contemplativo del solitario ante el manuscrito centra su atención sobre lo que lee y escribe y medita sin esforzar la memoria. Al volver sobre la secuencia leída o escrita el lector reconstruye la coherencia del conjunto sin pérdida literal. Si el hombre es un ser racional, cabe creer que el lenguaje sea más racional cuanto más reflexivo. El lector vuelve atrás, reflexiona, compone y recompone el pensamiento. Según los ilustrados la plenitud de la autonomía se alcanza cuando se piensa por uno mismo. Ilustrar es difundir el conocimiento acumulado para adquirir autonomía. La imprenta «es esencialmente un progreso técnico, tendrá repercusiones imprevisibles [...] una sociedad de élites va a evaporarse ante una sociedad de masas» (Febvre y Martin, 1962: 38-67). La letra impresa facilita la crítica reflexiva, el acceso igualitario al conocimiento. La sociedad abandona la minoría de edad intelectual y entra en la edad de la razón. Condorcet establecía una relación directa entre iluminismo e imprenta (1980: 165-219). El cogito puede interpretarse así, como una apertura de la conciencia crítica por la imprenta. Abre la capacidad reflexiva del lector. Alfabetizar para leer, escribir, almacenar el conocimiento leído y escrito posibilita acceder al que no sabe para ilustrarse, al conocimiento recopilado por otros. Con la imprenta y la lectura se pudieron multiplicar las copias para participar en el saber. Era la condición de posibilidad que pone a disposición de muchos el conocimiento de cada uno. «La acumulación de saberes y de conocimiento, [es] lo que lo convierte en un intermediario indispensable en la historia del pensamiento" (Barbier y Bertho, 1996: 11). Si la imprenta fue "la primera mecanización de una artesanía» del espíritu, el libro fue «la primera máquina de enseñar» (McLuhan, 1996: 187). Al abrir las puertas al lector, la imprenta propuso un patrón para la ilustración. La clase emergente de los intelectuales creyó disponer de un procedimiento para distribuir las funciones sociales en condiciones de igualdad en libertad. La multiplicación de copias propiciada por el automatismo tecnológico prometía a los iletrados alcanzar la kantiana «mayoría de edad».

Veamos el acto reflexivo como un tipo de «ensimismamiento» desde esta perspectiva. La lectura permite retener, volver atrás, repasar y meditar sobre lo escrito para criticarlo o reelaborarlo. Es una forma de "ensimismamiento". No la única. Podemos ensimismarnos ante un panorama, un cuadro o cualquier sentimiento que nos embargue. Según Ortega, el animal «no puede ensimismarse» (Ortega, 2010, X: 139 y s.). Si el hombre puede hacerlo es por su capacidad de aislarse provisoriamente del mundo o de contemplarlo absorto, es decir, absorbiendo en el acto contemplativo sus otras percepciones. 
También es meditar. Pero estas concomitancias muestran que las diferentes formas de meditar o de ensimismarse no se pueden predeterminar partiendo del análisis del medio o de la situación. Tampoco la relación entre medio y sujeto predetermina la actitud. La reflexión no procede del medio, ni la pasividad o la interactividad están vinculadas a la situación. Múltiples actitudes son compatibles con distintos medios. De aquí que si el libro no es identificable con lo que permite hacer o no hacer, tampoco la mirada es identificable con la pasividad irreflexiva. Entre otras cosas, los ilustrados pasaron por alto que la diferencia entre ver y leer no es de información - «una imagen vale más que mil palabras»—, sino que opone sincronía a linealidad. Se ve una foto fija y la palabra que la describe es lineal. Se necesitan muchas palabras para describir lo visto en un solo instante.

\section{De la cultura de masas a la cultura en red}

La crítica más dura a la cultura de masas fue la Dialéctica de la ilustración. Adorno y Horkheimer (1998: 165 y s.) presentaron como tesis una conjetura. La masificación era consecuencia de un designio para impedir que el ciudadano aprovechara las potencialidades inherentes al medio. El intercambio de las funciones emisora y receptora era impuesto: los destinatarios eran reducidos a la pasividad mientras los emisores controlaban la producción. Unos constituían la minoría dominante y otros, la mayoría dominada. Pero lo que puede decirse del medio puede también decirse de cualquier relación entre mayoría y minoría. Y eso es lo que advirtió Ortega y Gasset en La rebelión de las masas (2005: IV). Hoy es patente que la distinción entre minoría y masa es tan relativa y práctica como la relación entre el medio y la actitud del usuario. De hecho, la distinción permanece en todos los diversos órdenes de la vida social y trata de justificarse o de censurarse de diversas formas: la vanguardia se atribuye la representatividad de la conciencia de clase; el disidente representa la inteligencia crítica; Greenpeace simboliza la pureza de los mares; el artista solitario, la sublimación del arte; el mánager triunfante significa la eficiencia; el especialista es maestro del aprendiz; el mejor jugador lidera su equipo. La diferencia entre seguir a o ser seguido por es llamativa en el escenario igualitario de las redes.

La argumentación de los críticos de la masificación se desmoronó cuando la tecnología llevó a la comunicación de masas las condiciones de la comunicación interpersonal. La comunicación audio-escrita-visual es universalmente accesible a todo individuo a través de los self media (Cloutier, 1973). En este espacio virtual multiforme el espectador es actor, porque puede retener, volver atrás, modificar y rectificar. La innovación dejó al descubierto que los rasgos de la masificación cultural no procedían de los controles para limitar la potencialidad ni de las situaciones del sujeto en el proceso comunicativo. Quedó en evidencia que la crítica se había basado en argumentos ad hoc. El planteamiento crítico fue trastocado por McLuhan (1996). Los medios extienden los sentidos parcialmente cuando son «sistemas cerrados», como, a 
su juicio, lo es «la rueda», «el alfabeto» o «la imprenta», es decir, plantean una relación discriminatoria. Los medios escritos reducen el entorno a los alfabetizados y excluyen a los analfabetos. Según McLuhan amputan la interacción con otros sentidos mientras se lee. Esto es discutible: si el entorno libresco fuera excluyente de la acción de los demás sentidos, estos quedarían «amputados». Por eso pensó que el medio amputa (McLuhan, 1996: 62 y s.) en la relación social la comunicación oral propia de la aldea primitiva y que, a partir de su difusión por la imprenta, la amputación aumentaba con el libro. Pero no es necesariamente así. Resulta cierto que la visualidad ensimismada de la lectura puede no interaccionar con el intercambio acústico, pero no porque la alfabetización ampute a los sentidos, sino porque promociona el ensimismamiento. Para aprovechar la lectura, la actitud del lector ha de modular o filtrar la alerta sensorial, pero lo mismo ocurre en una sala de cine o en un concierto de música clásica. La escritura dispuso del monopolio de la grabación y de la difusión durante la era Gutenberg hasta que llegó el teléfono. Desde entonces las aplicaciones fueron tan variadas y socialmente útiles para el registro y la conservación de documentos, que se entiende que McLuhan tratara la etapa impresa como una fase distintiva de la modernidad que amputaba la comunicación oral. No tenía razón, pues si prolongaba la acción sensorial, no la sustituía. Permitía que los sentidos se focalizaran en la situación cuando les era ventajoso centrarse en ella. Es decir, no era una amputación, sino que más bien, como decía Ortega, facilitaba el ensimismamiento.

Obviamente, McLuhan juega con cierta arbitrariedad con la analogía de términos como cerrado y abierto, frío y caliente en que se apoya. Es aventurado separar en el hombre primitivo su condición de espectador de la de oyente o imputar a la imprenta que amputara la comunicación entre vecinos cuando los vecindarios eran como bolsas de patatas yuxtapuestas sin relaciones mutuas. Así los describía Marx en El 18 Brumario de Luis Bonaparte (2008: 109-110). También la actividad de cazar requiere una concentración como la fijación en la lectura. Cualquier actividad que requiera concentrarse es «cerrada», en el sentido en que suele usar McLuhan esta palabra cuando se refiere al alfabeto o a la imprenta. Mas anticipó que las nuevas tecnologías transformarían las relaciones de proximidad de la comunicación entre vecinos en relaciones cara a cara a distancia ilimitada. Previó que esa transformación valdría luego para explicar que la atención al televisor no era una dependencia pasiva, sino tan activa como para adelantarse al confuso flujo de las redes sociales (McLuhan, 1969). Que las nuevas tecnologías transmutaran un espacio visual que hubiera cerrado la imprenta en un espacio acústico democráticamente abierto es harina de otro costal.

El cumplimiento de la previsión de McLuhan de que la comunicación lineal de la imprenta volvería a ser, gracias a la tecnología, tan reticular como lo fue en la aldea tribal, dejó en evidencia a los críticos de la masificación cultural. La red mostró que, tras esa relación lineal, el sistema no camuflaba un propósito sistémico y que el medio de comunicación no era un instrumento que canalizase un «designio» que impedía la fructificación de las potencialida- 
des de interacción inherentes al medio. Si esa limitación no se vinculaba a un impedimento sino al propio desarrollo tecnológico, se podía descartar el argumento crítico. Con las redes ya no cabe imputar el «desencanto» por el desvanecimiento ilustrado a poderes ocultos para mantener la asimetría social, porque todos los usuarios son, comunicativamente hablando, tan poderosos como el que más. La cuestión que discutir se traslada a la validez de los presupuestos básicos en que se gestó la crítica de la modernidad.

\section{Progresiva regresión de la retórica en la red}

Ortega había hablado de cómo el pasado se mantiene en el presente distinguiendo tres fases. La de la técnica del azar primitiva, la artesanal que finaliza con el Renacimiento y la de la máquina de producción en serie. El hombre primitivo ideaba su pintura por azar, el copista era un artesano, la imprenta «una máquina», un «aparato que actúa por sí mismo» (2006: V, 598). Separa con precisión la artesanía del glosador de la mecanizada galaxia Gutenberg. La vuelta de McLuhan a las condiciones aldeanas en la galaxia global es solo una analogía con situaciones que ningún supuesto puede considerar equivalentes. No es posible retrotraerse al pasado de la aldea tribal, porque sus condicionamientos son ajenos a los cambios que desembocaron en la globalización. Pero la inversa no es cierta. Por eso, aunque el tránsito del manuscrito a la imprenta pueda entenderse como una disociación de la unidad emotivo-cognoscitiva que imperó durante un milenio de retórica y oratoria, la recomposición de esa unidad, disuelta desde el cogito cartesiano, no es condición suficiente para revivir o recomponer una retórica milenaria. Las imágenes del pasado se conservan porque se experimentaron, no pueden reconstruirse como si se mantuvieran las condiciones que las hicieron posibles, porque, socialmente hablando, han cambiado. El pasado es "un país extraño", desde el presente da paso al futuro, pero, siendo extrańo, "la nostalgia lo ha hecho el país extraño con mercado turístico más saneado de los que existen" (Lowenthal, 1998: 29). Eso lo ponía en valor La rebelión de las masas y lo vuelve a colocar sobre el tapete Baumann en Retrotopía (2017: 11 y s.). El igualitarismo de la red disuelve las normas del pasado sin disponer de más recambio que la mirada retrospectiva a la circunstancia que la gestó.

Hace todavía poco tiempo las relaciones a grandes distancias estaban limitadas por el tipo de medio. Con la red, las condiciones de la intercomunicación individualizada se han desprendido del condicionamiento de la proximidad. Abiertas a todas las situaciones, el medio solo interfiere para facilitarlas. $\mathrm{Al}$ romper la barrera de la distancia para iniciar o mantener enlaces personales, las redes no suministran, sin embargo, nuevos modos de relacionarse, sino nuevos modos de establecer el contacto para la relación, es decir, para agrupar, consolidar u olvidar los contactos. Modos tan versátiles y efímeros como lo sea el contacto. Los modos de la comunicación virtual no son equivalentes in toto a la proximidad física. La diferencia entre ambos está por precisar. Pero el acercamiento es tan rápido que las diferencias que se precisen 
hoy pueden no valer mañana o acaso esta tarde. De momento, en el espacio virtual, cuanta actividad no dependa del organismo queda abierta a la comunicación. Ver, hablar, pensar y oír son ¿todavía? actividades biológicas. Padecer, entender o sentir pueden nacer en la conciencia y no regresar a ella en las mismas condiciones en la relación virtual que en el contacto físico. En la lejanía de la proximidad virtual lo táctil se reduce al procedimiento. La génesis es propia de un yo que mira, escucha, conoce, ama o sufre. Las acciones ligadas a la sensación, como el gusto, el placer, el sentimiento, tienen un origen, pero también un destino que la virtualidad solitaria o la distancia no acaba de complacer plenamente.

En las redes conectamos selectivamente sin importar la distancia que separa a los interlocutores, formamos grupos evanescentes de cohesión discontinua, pero también pueden servir para afianzar las establecidas. Esta diversidad no difiere mucho de los contactos de la vida cotidiana (Goffman, 1981), la amplía sin reconocer fronteras. "Nihil novum sub sole.» Siempre ha habido situaciones pasajeras, otras más sustantivas, conocidos y amigos, encuentros ocasionales y relaciones afectivas. ¿Qué cambia? Puede que la volatilidad de la red se manifieste mejor en la fugacidad de las relaciones que suscita y en la efímera intensidad de su permanencia (Núñez Ladevéze y Vázquez, 2020). Las constituidas en la cercanía tienen más garantía de consistencia que en la disipación reticular. Nada impide que la red sea un centro de reunión que acoja sin restricciones. No hay brechas que la red abra, hay brechas que el usuario abre o que procura que sigan abiertas.

Como este proceso de transferencia es individualista por ser igualitario, y viceversa, no cabe apelar a que lo dirige un decurso normativo, un designio interior para explicar que el proceso que las mantiene sea siervo del sistema que lo promueve. Los usuarios aceptan las condiciones del acceso. Por eso, Bauman y Lyon (2014) califican esa aceptación de «servidumbre voluntaria». Que esta sea la resultante del comportamiento acumulativo de individuos socialmente conscientes de su autonomía, que disponen de medios para decidir sus contactos, satisfacer su ansiedad, adherirse a sus motivaciones y prejuicios, frustra toda pretensión iluminista. El igualitarismo de la red lo aportó la industria tecnológica tras el fracaso del comunismo en su pugna con el capitalismo. Los fracasados la utilizan hoy tan complacientes como el control de los recursos se desplaza de Occidente a Oriente. Todos cuantos individualmente se rebelan contra el sistema usan la red tan despreocupadamente para preocuparse de sus efectos como cuantos tratan de preservar un sistema que promueve la fugacidad que tanto nos preocupa. Ortega y Gasset previó la fugaz «ubicuidad» de la red y la llamó «rebelión de las masas».

La derrota ideológica da carta de naturaleza a las ideologías frustradas. Si no hay nada que ofrecer, se sustituye en la red por lo que haya que reprochar. Las ideologías de la sospecha transmutan en masoquismo ideológico. Cierran los ojos a la causa del fracaso oculta en algún rincón de Chernóbil, del archipiélago Gulag, Auschwitz o Tiananmen, para fijarlos en el desencanto. Esta frustración que anticipó Ortega y Gasset va más allá de las ilusiones idealistas 
o materialistas. Como el progreso científico-técnico es un medio independiente de la ideología, ha desbordado las fronteras culturales del capitalismo industrial y abastecido con la técnica occidental a los colonizados por esa técnica. Europa no manda en el mundo (Ortega, 2004: IV, segunda parte). Llamar a China, Irán o India "países emergentes» es desfigurar que son potencias «imperialistas». Si en Occidente preocupaban las «brechas» de la desigualdad, la disparidad de usos del medio comunicativo, en Oriente se permite al desencanto masoquista abrir una nueva brecha antes de haber cerrado la anterior. Siempre queda en la mano encontrar un nuevo argumento contra el sistema que cobija a todos por igual.

\section{Referencias bibliográficas}

Adorno, T. y Horkheimer, M. (1998). Dialéctica de la ilustración: Fragmentos filosóficos. Madrid: Trotta.

ARMENTEROS, E. (2004). El pragmatismo de Ortega: Una impronta de su filosofía. Universidad de Sevilla. Tesis doctoral.

Austin, J. L. (1971). Palabras y acciones: Cómo hacer cosas con palabras. Barcelona: Paidós. Edición original: How to do Things with Words. Harvard: President and Fellows of Harvard College, 1962.

Barbier, F. y BerTho, L. C. (1999). Historia de los medios: De Diderot a internet. Buenos Aires: Colihue.

BAUMAN, Z. (2017). Retrotopía. Barcelona: Paidós.

BAUMAN, Z. y LYON, D. (2014). Vigilancia líquida. Barcelona: Planeta-Espasa.

BECKER, T. (1981). «Teledemocracy: Bringing power back to the people». The Futurist, 15 (6) (diciembre), 6-9.

ClouTIER, J. (1973). La communication audio-scripto-visuelle á l'heure des self-media ou l'ère d'Emerec. Montreal: Presses de l'Université.

CONDORCET (1980). Bosquejo de un cuadro histórico de los progresos del espiritu humano. Madrid: Editora Nacional.

CoOley, Charles H. (1906). Social Organization: A Study of the Larger Mind. Nueva York: Scribner's Sons.

Debord, G. (1995). La sociedad del espectáculo. Santiago de Chile: Naufragio. Edición original: La société du spectacle. París. Buchet Chastel, 1967.

Febvre, L. y Martin, H. (1962). La aparición del libro. México: Hispano Americana.

GOFFMAN, E. (1981). La presentación de la persona en la vida cotidiana. Buenos Aires: Amorrortu.

GUTIÉRREZ SiMÓN, R. (2020). «Ortega y el pragmatismo norteamericano: Estado de la cuestión y prejuicio plausible». Revista de Estudios Orteguianos, 40, 186-198.

Horkheimer, M. (1970). Sobre el concepto del hombre y otros ensayos. Buenos Aires: Sur.

LOWENTHAL, D. (1998). El pasado es un país extraño. Madrid: Akal.

MARX, C. (2008). El 18 Brumario de Luis Bonaparte. Madrid: Fundación Federico Engels. Recuperado de $<$ https://bit.ly/38HfYXO >.

MCLUHAN, M. (1969). La galaxia Gutenberg. Madrid: Aguilar.

- (1996). Comprender los medios de comunicación: Las extensiones del ser humano. Barcelona: Paidós.

MEAD, G. H. (1991). «La génesis del self y el control social». REIS, 55, 165-181. 
NúNEEZ LadevÉze, L. y VÁzQuez BARrio, T. (coords.) (2020). Redes líquidas: De las audiencias masivas a las audiencias reticulares. Madrid: Síntesis.

NúÑEZ LADEVÉZE, L.; VÁZQUEZ BARRIO, T. y ÁlvarEZ DE MON, I. (2019). «Del "engaño de masas" de la teoría crítica al "vecindario indefinido" de Bauman». Revista Latina de Comunicación Social, 74, 1114-1131. <https://doi.org/10.4185/RLCS-2019-1374>

NúÑez Ladevéze, L.; VÁzQuez Barrio, T. y NúŃEz CANal, M. (2019). «El tránsito a la modernidad líquida global: La rebelión de las masas en el vecindario indefinido». Arbor, 196 (797), 568. <https://doi.org/10.3989/arbor.2020.797n3005>

ORTEGA Y GASSET, J. (2004-2010). Obras completas. Madrid: Fundación OrtegaMarañón-Santillana.

El tema de nuestro tiempo, 2005, III, 559-662.

La rebelión de las masas, 2005, IV, 349-530.

Meditación de la técnica, 2006, V, 551-608.

Ideas y creencias, 2006, V, 657-745.

Historia como sistema, 2006, VI, 45-83.

En torno a Galileo, 2006, VI, 367-506.

El hombre y la gente: Curso de 1949-1950, 2010, X, 139-327.

SARTORI, G. (1998). Homo videns: La sociedad teledirigida. Madrid: Taurus.

SAUSSURE, F. de (1971). Curso de lingüistica general. 9. a ed. Buenos Aires: Losada.

SPENGLER, O. (1923-1927). La decadencia de Occidente. Madrid: Espasa.

VAN DIJK, J. (2000). "Models of Democracy and Concepts of Communication». En: HACKer, K. L. y VAN Dijk, J. (ed.). Digital Democracy: Issues of Theory and Practice. Londres: Sage.

ZAREMberG, G. y WeLP, Y. (2020). «Más allá de enfoques utópicos y distópicos sobre innovación democrática». Recerca: Revista de Pensament i Anàlisi, 25 (1), 71-94. 
